\title{
Structural and Optical Properties of Zirconia Nanoparticles by Thermal Treatment Synthesis
}

\author{
Aysar S. Keiteb, ${ }^{1,2}$ Elias Saion, ${ }^{1}$ Azmi Zakaria, ${ }^{1}$ and Nayereh Soltani ${ }^{3}$ \\ ${ }^{1}$ Department of Physics, Faculty of Science, Universiti Putra Malaysia (UPM), 43400 Serdang, Selangor, Malaysia \\ ${ }^{2}$ College of Health and Medical Technologies, Baghdad, Iraq \\ ${ }^{3}$ Young Researchers and Elite Club, Islamic Azad University, Shahr-e-Qods Branch, Tehran, Iran
}

Correspondence should be addressed to Aysar S. Keiteb; aysarph.d@gmail.com

Received 26 November 2015; Revised 8 May 2016; Accepted 22 May 2016

Academic Editor: Oscar Perales-Pérez

Copyright (C) 2016 Aysar S. Keiteb et al. This is an open access article distributed under the Creative Commons Attribution License, which permits unrestricted use, distribution, and reproduction in any medium, provided the original work is properly cited.

\begin{abstract}
Zirconium dioxide nanoparticles with monoclinic blended structure were successfully synthesized by thermal treatment method using zirconium (IV) acetate hydroxide as the metal precursor, polyvinylpyrrolidone as the capping agent, and deionized water as a solvent. The chemicals were mixed and stirred to form a homogeneous solution and hereafter directly underwent calcination to attain the pure nanocrystalline powder, which was confirmed by FTIR, EDX, and XRD analyses. The control over the size and optical properties of nanoparticles was achieved through changing in calcination temperatures from 600 to $900^{\circ} \mathrm{C}$. The obtained average particle sizes from XRD spectra and TEM images showed that the particle size increased with increasing calcination temperature. The optical properties which were investigated using a UV-Vis spectrophotometer showed a decrease in the band gap energy with increasing calcination temperature due to the enlargement of the particle size. These results prove that, by eliminating drying process $(24 \mathrm{~h})$ in the present thermal treatment method, size-controlled zirconia nanoparticles were conveniently manufactured with a reduction of synthesize time and energy consumption, suitable for large-scale fabrication.
\end{abstract}

\section{Introduction}

$\mathrm{ZrO}_{2}$ (zirconia) is a material of great technological importance, having good natural color, high strength, transformation toughness, high chemical stability, excellent corrosion resisting material, and chemical and microbial resistance $[1,2] . \mathrm{ZrO}_{2}$ is a wide band gap p-type semiconductor that exhibits abundant oxygen vacancies on its surface. The high ion exchange capacity and redox activities make it useful in catalysis [3]. $\mathrm{ZrO}_{2}$ is also an important dielectric material for potential application as an insulator in transistors in future nanoelectric devices [4]. Garcia et al. have highlighted its potential to replace $\mathrm{SiO}_{2}$ in advanced metal oxide semiconductor (MOS) devices and in optical applications [5].

$\mathrm{ZrO}_{2}$ nanoparticles have found uses in solid oxide fuel cells [6] and in nitrogen oxide, oxygen gas sensors [7]. The fully stabilized $\mathrm{ZrO}_{2}$ nanoparticles are also well suited for high temperature energy conversion systems, attributed to its high oxygen ion transport capabilities and long-term stability.
$\mathrm{ZrO}_{2}$ is a wide band gap p-type semiconductor that exhibits abundant oxygen vacancies on its surface.

$\mathrm{ZrO}_{2}$ has three well-defined crystal phases, that is, cubic (c- $\left.\mathrm{ZrO}_{2}\right)$, tetragonal $\left(\mathrm{t}-\mathrm{ZrO}_{2}\right)$, and monoclinic $\left(\mathrm{m}-\mathrm{ZrO}_{2}\right)$, under normal atmosphere and at different temperatures [8, 9]. Generally, $\mathrm{m}-\mathrm{ZrO}_{2}$ phase is thermodynamically stable up to $1100^{\circ} \mathrm{C}, \mathrm{t}-\mathrm{ZrO}_{2}$ phase exists in the temperature range of $1100-2370^{\circ} \mathrm{C}$, and the cubic phase is found at higher temperature above $2370^{\circ} \mathrm{C}$ [10].

Several techniques are available for producing zirconia nanoparticles, such as sol/gel method [11], vapor phase method [12], pyrolysis [13], spray pyrolysis [14], hydrolysis [15], hydrothermal [16], and microwave plasma [17]. However, these methods faced many limitation factors such as complicated procedures, high reaction temperature, long reaction time, toxic reagents and by-products use, and high cost of production, which made it difficult to prepare zirconia nanoparticles on a large-scale production. 
Recently, thermal treatment method has been used in syntheses of several nanomaterials including metals ferrite nanoparticles [18-21], zinc oxide nanoparticles [22], cadmium oxide nanoparticles [23], and thermoluminescence nanomaterials [24]. The drying process for $24 \mathrm{~h}$ at $80^{\circ} \mathrm{C}$ before undergoing calcination is a common feature in the thermal treatment synthesis. However, in the synthesis of $\mathrm{ZrO}_{2}$ nanoparticles, a solution containing metal precursor and capping mediator is directly submitted to calcination, thus eliminating the drying process and reducing the preparation time and the energy consumption. This modified thermal treatment synthesis looks greener than the earlier thermal treatment methods for fabrication of metal oxide nanoparticles such as nanosized $\mathrm{ZrO}_{2}$ powder, a necessity for large-scale industrial application. The technique is relatively environmentally friendly as no toxic material discharges into the drainage system. The effect of calcination temperature on the structural, particle size, and optical properties of $\mathrm{ZrO}_{2}$ nanoparticles is also investigated using various techniques.

\section{Experimental}

2.1. Materials. Polyvinylpyrrolidone (PVP MW $=58000 \mathrm{~g} /$ mol) stock obtained from Sigma Aldrich was used as a capping agent. Zirconium acetate, $\left[\mathrm{C}_{12} \mathrm{H}_{36} \mathrm{O}_{24} \mathrm{Zr}_{3}\right]$ with high purity stock supplied by Sigma-Aldrich Chemistry (MW = $285.36 \mathrm{~g} / \mathrm{mol}$ ), was used as a metal precursor and deionized water was used as a solvent. All chemicals were used without further purification.

The PVP solution is made by dissolving $3 \mathrm{~g}$ of PVP powder in $100 \mathrm{~mL}$ of deionized water at a temperature of $70^{\circ} \mathrm{C}$ and magnetically stirred for $2 \mathrm{~h}$. The metal precursor of $0.2 \mathrm{mmol}$ was added to the PVP solution and stirred continuously for another $2 \mathrm{~h}$ until a semitransparent solution was obtained with no significant precipitation of materials. The mixture was directly placed in an alumina crucible for calcination at different temperatures ranging from 600 to $900^{\circ} \mathrm{C}$ in a retention time of $3 \mathrm{~h}[25,26]$, to decompose the polymer and to crystallize the metal oxide nanoparticles.

2.2. Characterization Procedures. Thermal analysis of initial solution dried at $30^{\circ} \mathrm{C}$ was investigated by Thermogravimetric Analysis (TGA) and Derivative Thermogravimetry Analysis (DTG) using a Perkin Elmer Thermal Analyzer model TGA7/DTA7 in the presence of $\mathrm{N}_{2}$ with $10^{\circ} \mathrm{C} / \mathrm{min}$ heating rate from room temperature to $1000^{\circ} \mathrm{C}$ to optimize the heat treatment program. Fourier transform infrared spectroscopy (FTIR) was used to study the chemical composition of samples using Perkin Elmer Spectrum 1650. Energy dispersive Xray (EDX) measurements were performed under a variable pressure scanning electron microscope (VPSEM, LEO 1455) with an Oxford INCA EDX 300 microanalysis attachment. The crystal phase of prepared samples was determined by $\mathrm{X}$-ray diffraction (XRD) technique using Shimadzu-6000 diffractometer utilizing $\mathrm{Cu} \mathrm{K} \alpha(0.154 \mathrm{~nm})$ radiation. The morphology and average particle size of the nanocrystalline powder were evaluated using Hitachi H-7100 Transmission Electron Microscope (TEM) operating at accelerating voltage of $100 \mathrm{kV}$. The average size and size distribution of nanoparticles were determined by Image tool software. The optical reflectance spectra of samples were recorded using the UVVis spectrometer (Shimadzu-UV1650PC SHIMADZU), and the band gap energy was evaluated from the reflectance spectra using the Kubelka-Munk function. All the mentioned measuring devices above were calibrated before conducting the measurements where applicable.

\section{Result and Discussion}

3.1. The Role of PVP in Synthesis Process. According to previous studies [27-29], the use of PVP in nanoparticles synthesis is very imperative as it plays four crucial roles: control the growth of nanoparticles, limit the agglomeration of nanoparticles, enhance the degree of crystallinity degree of particles, and produce uniform particle size distribution.

In the first step of making initial solution, PVP works as a stabilizer or a mediator for dissolving complex metallic salts through steric and electrostatic stabilization of the amide groups of the pyrrolidone rings and the methylene groups. By dissolving zirconium acetate in PVP solution, strong ionic bonds between the amide group of polymeric chain and metallic ions, $\mathrm{Zr}^{4+}$. The uniform immobilization of metallic ions in the cavities of the polymer chains tends to form nanoparticles with uniform distribution. In the calcination step, although the organic matters will be decomposed to gasses such as $\mathrm{N}_{2}, \mathrm{NO}, \mathrm{CO}$, or $\mathrm{CO}_{2}$, trace of carbon residual that bonded on the surface of nanoparticles, which takes higher temperatures to decompose as shown by the weight loss in (Figure 1), can protect them from uncontrolled growth and agglomeration $[21,28,29]$.

3.2. Thermal Analysis (TGA/DTG). Thermal analysis of initial solution allows the optimization of the heat treatment program and shows the suitable temperature at which calcination process must take place. The Thermogravimetric Analysis accompanied with its derivative form (TGA-DTG curves) was implemented for the initial solution dried at $30^{\circ} \mathrm{C}$ and its thermogram is clearly illustrated in (Figure 1). The TGA curve demonstrates two weight loss steps. The first insignificant weight loss ( $22 \%)$ occurred between $\sim 30$ and $\sim 250^{\circ} \mathrm{C}$, which attributed to the trapped moisture and acetate in the sample, respectively, whereas the second one, the drastic weight loss between 400 and $470^{\circ} \mathrm{C}$, is due to the decomposition of organic residues (i.e., PVP). Starting at the temperature of $471^{\circ} \mathrm{C}$, the remaining material was almost pure $\mathrm{ZrO}_{2}$ nanoparticles with some left-out carbonaceous product formed as a result of overheated PVP content which is confirmed by FTIR, EDX, and XRD results. The sharp and strong peaks in DTG curve with maxima at $\sim 62$ and $436^{\circ} \mathrm{C}$ also validate the minor weight loss of trapped moisture and combustion of PVP, respectively.

3.3. Phase Composition Analysis (FTIR). The FTIR spectra of the samples before and after calcination are depicted in (Figure 2) in the wavenumber ranging from 280 to $4000 \mathrm{~cm}^{-1}$. The presence of absorption peaks at wavenumbers above 


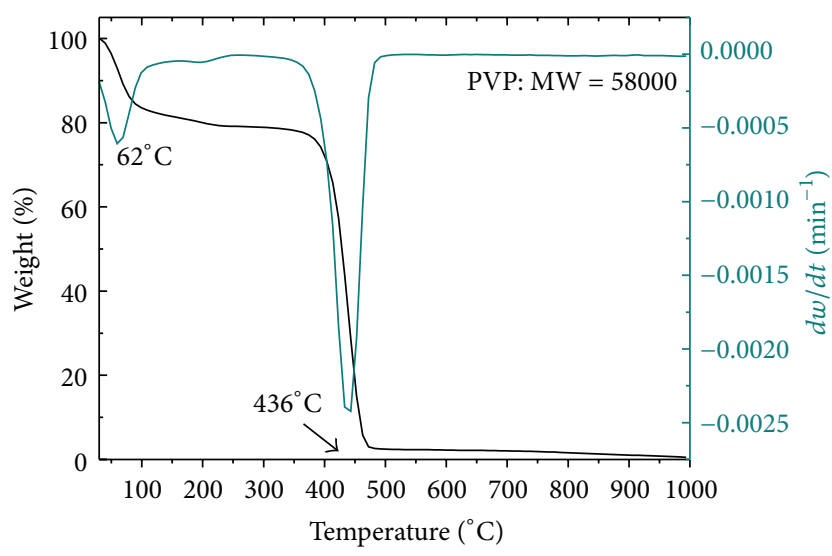

FIGURE 1: Thermogravimetric (TG) and thermogravimetric derivative (DTG) curves of initial solution at a heating rate of $10^{\circ} \mathrm{C} / \mathrm{min}$.

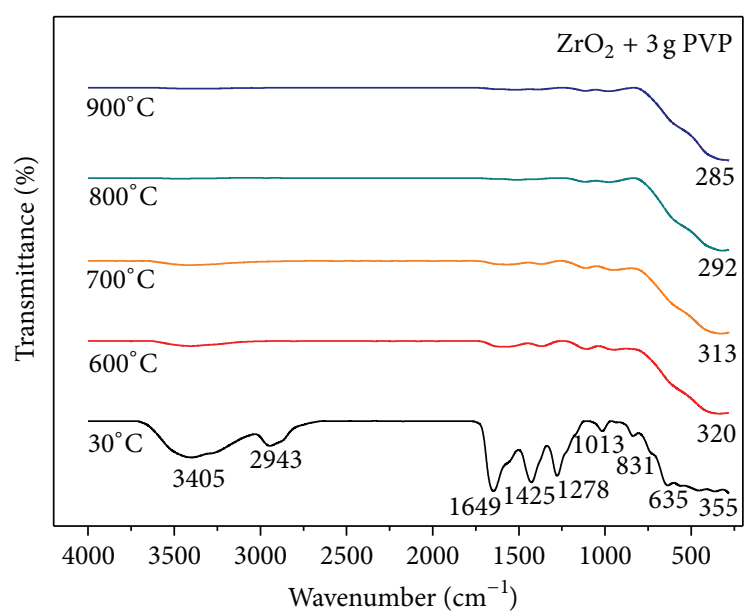

FIgURE 2: FTIR spectrum of $\mathrm{ZrO}_{2}$ with nanoparticles $3 \mathrm{~g}$ of PVP at different calcination temperatures.

$600 \mathrm{~cm}^{-1}$ in the sample before calcination $\left(30^{\circ} \mathrm{C}\right)$ indicates the presence of covalent bonds from organic sources from acetate and PVP. The absorption peaks at wavenumber of 3405,2943 , and $1649 \mathrm{~cm}^{-1}$ are assigned to $\mathrm{N}-\mathrm{H}, \mathrm{C}-\mathrm{H}$, and $\mathrm{C}=\mathrm{O}$ stretching vibrations, respectively. Further, the absorption peak found at $1425 \mathrm{~cm}^{-1}$ is stemmed from a vibration due to $\mathrm{C}-\mathrm{H}$ bending in methylene group, while the band at $1278 \mathrm{~cm}^{-1}$ is associated with $\mathrm{C}-\mathrm{N}$ stretching vibration. Finally, two peaks located at 831 and $635 \mathrm{~cm}^{-1}$ are linked to vibrations occurring due to $\mathrm{C}-\mathrm{C}$ ring and $\mathrm{C}-\mathrm{N}=\mathrm{O}$ bending [30]. The calcination of samples at 600 to $900^{\circ} \mathrm{C}$ has led to the relative disappearance of covalent bands of peaks between 4000 and $1000 \mathrm{~cm}^{-1}$, which can be implicitly referred to as decomposition of PVP used during the preparation of the sample. The remaining peaks from 355 to $285 \mathrm{~cm}^{-1}$ derived from ionic bond conforming the formation of crystalline $\mathrm{ZrO}_{2}$ nanoparticles [31].

3.4. Elemental Composition (EDX). The elemental composition of $\mathrm{ZrO}_{2}$ nanoparticles was analyzed by EDX as shown

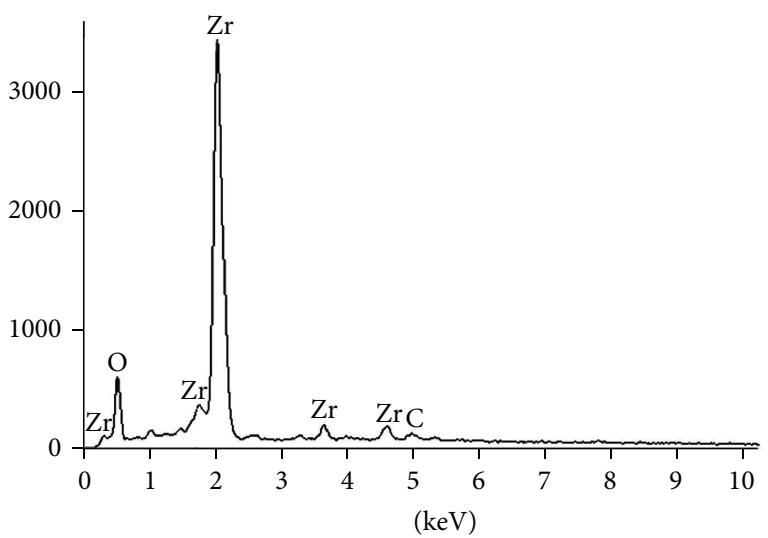

FIGURE 3: EDX spectrum of $\mathrm{ZrO}_{2}$ nanoparticles calcined at temperature of $600^{\circ} \mathrm{C}$.

in Figure 3. The host material of $\mathrm{ZrO}_{2}$ nanoparticles exhibits four elemental peaks; three for zirconium element located at $0.27,1.85$, and $2.17 \mathrm{keV}$ and one for oxygen element located at $0.5 \mathrm{keV}$. From EDX data, the weight ratio of $\mathrm{Zr}: \mathrm{O}$ is around $69: 26$. The existence of some low intensity peaks in the spectrum is attributed to the traces of carbon residual in the sample, which is due to the uncompleted decomposition of PVP at $600^{\circ} \mathrm{C}$. The estimated weight ratio of carbon residual in the samples is less than 5\% (Figure 1), so that the reaction yield of zirconia nanoparticles can be determined by weighing the products.

3.5. Structural Analysis (XRD). The crystal structure, crystallinity, and crystallite size of synthesized $\mathrm{ZrO}_{2}$ nanoparticles have been investigated by generating diffraction patterns, $\mathrm{XRD}$, from the crystalline powder samples at ambient temperature in $2 \theta$ range of $20^{\circ}-70^{\circ}$. The XRD profile of the assynthesized and thermally treated samples is demonstrated in Figure 4 . For the as-synthesized sample, (dried initial solution at $30^{\circ} \mathrm{C}$ ), there is a characteristic noncrystallized phase of PVP in its amorphous structure. However, by applying different calcination temperatures, the crystalline behavior of the sample begins to appear with peaks indexed by (111), (002), (022), (202), (113), (311), and (222) planes (ICDD PDF 79-1768) which are assigned to monoclinic zirconium blended structure as reported in previous works [20,21]. With increasing of calcination temperature, the diffraction peaks become sharper and narrower and their intensity notably increases, which is a sign of the significant enhancement in crystallinity of the $\mathrm{ZrO}_{2}$ nanocrystals that originates from the increment of crystalline planes caused by the particle size enlargement [12].

Scherrer's formula was utilized to compute the crystallite sizes from the full width of the half-maximum (FWHM) peak broadening of the (111) peak of the XRD patterns:

$$
D=\frac{0.9 \lambda}{\beta \cos \theta},
$$

where $D$ is the average crystallite size, $\lambda$ is the $\mathrm{X}$-ray wavelength, that is, $0.1542 \mathrm{~nm}, \beta$ is the angular line width 


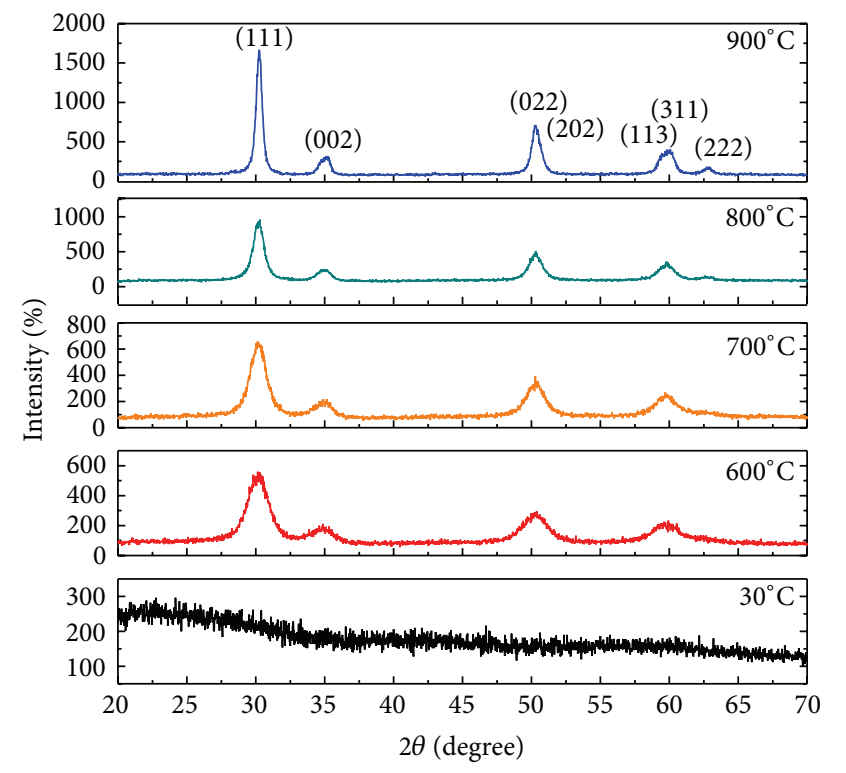

FIGURE 4: XRD pattern of $\mathrm{ZrO}_{2}$ nanoparticles with various calcination temperatures.

TABLE 1: The calculated crystallite sizes and particle size according to different calcination temperatures.

\begin{tabular}{lccc}
\hline Sample $\left({ }^{\circ} \mathrm{C}\right)$ & $2 \theta^{\circ}$ & $\begin{array}{c}\text { Crystallite size } \\
D_{\text {XRD }}(\mathrm{nm})\end{array}$ & $\begin{array}{c}\text { Particle size } \\
D_{\text {TEM }}(\mathrm{nm})\end{array}$ \\
\hline 600 & 30.248 & 6 & 7 \\
700 & 30.246 & 10 & 12 \\
800 & 30.193 & 17 & 19 \\
900 & 30.261 & 28 & 32 \\
\hline
\end{tabular}

of full width of half-maximum (FWHM) intensity, and $\theta$ is Bragg's angle. Table 1 presents the calculated crystallite sizes corresponding to different calcination temperatures. Based on the result shown in this table, it is observed that the crystallite size increases allometrically with increasing of calcination temperature, from $6 \mathrm{~nm}$ at $600^{\circ} \mathrm{C}$ to $28 \mathrm{~nm}$ at $900^{\circ} \mathrm{C}$.

3.6. Morphology and Size Distribution. TEM micrographs of semiconducting $\mathrm{ZrO}_{2}$ nanoparticles at different calcination temperatures of $600,700,800$, and $900^{\circ} \mathrm{C}$ are shown in Figure 5.

From the illustration, a uniform morphology with adequate distribution was achieved. The particle size distribution which is calcination temperature dependent and has growth mechanism lies in the range of $\sim 7-32 \mathrm{~nm}$. A nucleation process started where $\mathrm{Zr}^{4+}$ reacts with two $\mathrm{O}^{2+}$ from air to form $\mathrm{ZrO}_{2}{ }^{0}$ molecules, which are distributed uniformly (as discussed in Section 3.1) and then immediately undergo agglomeration to form $\mathrm{ZrO}_{2}{ }_{2}$ or $\mathrm{ZrO}_{2}{ }_{m}{ }_{m}(m>2)$ nanoparticles, when the capping PVP polymer gradually decomposed during calcination starting at about $471^{\circ} \mathrm{C}$. Large $\mathrm{ZrO}_{2}{ }^{0}{ }^{m}$ nanoparticles can agglomerate further with other $\mathrm{ZrO}_{2}{ }^{0}{ }_{n}$ nanoparticles at higher calcination temperature to form even
TABLE 2: Summary of calcination temperatures and equivalent band gap energies.

\begin{tabular}{lcc}
\hline Calcination temp. $/{ }^{\circ} \mathrm{C}$ & Particle size/nm & Energy bandgap/eV \\
\hline 600 & 7 & 4.83 \\
700 & 12 & 4.81 \\
800 & 19 & 4.79 \\
900 & 32 & 4.74 \\
\hline
\end{tabular}

larger $\mathrm{ZrO}_{2}{ }^{0}{ }_{m+n}$ nanoparticles. The increment of particle size with calcination temperature is supposed to be due to removal of trace of carbon (Figure 1) on the particles surface that forced neighboring particles to agglomerate and creating eventually larger particles. The average particle sizes obtained from TEM images are in a good agreement with the XRD profile results presented in Table 1.

3.7. Optical Properties. The optical band gap energies for calcined samples at different temperatures were determined from reflectance spectra using Kubelka-Munk equation:

$$
\left(F\left(R_{\infty}\right) \cdot h v\right)^{2}=A\left(h v-E_{g}\right),
$$

where $F\left(R_{\infty}\right)$ is the so-called reemission parameter or Kubelka-Munk function, $h v$ is the incident photon energy, $R_{\infty}$ is the diffuse reflectance that is obtained from $R_{\infty}=$ $R_{\text {sample }} / R_{\text {standard }}$, and $A$ is a constant depending on the transition probability and the diffuse reflectance $R_{\infty}$ [14].

The values of $\left(F\left(R_{\infty}\right) \cdot h v\right)^{2}$ versus $(h v)$ were plotted for calcined samples at different temperatures as illustrated in Figure 6. Straight lines were drawn to fit the experimental curves and were prolonged to cut off the $(h v)$ axis in order to determine the optical band gap values of the $\mathrm{ZrO}_{2}$ nanoparticles at different calcination temperatures. It was found that the optical band gap has decreased with the elevation of calcination temperature from $4.83 \mathrm{eV}$ at $600^{\circ} \mathrm{C}$ to $4.74 \mathrm{eV}$ at $900^{\circ} \mathrm{C}$ as shown in Table 2 . The decrement of the energy band gap with the increasing calcination temperatures is credited to the growth of the particle and crystallinity improvement, according to the XRD analysis.

It is supposed that, as the particle size increases, the number of atoms that form a particle also increases, consequently rendering the valence and conduction electrons more attractive to the ions core of the particles and hence decreasing the band gap of the particles [22]. Perhaps the contribution of phonons has a role in trapping electrons and consequently influences the band gap energy level during optical properties measurement [32].

\section{Conclusions}

Zirconia nanoparticles have been successfully synthesized by direct calcination of an aqueous solution containing zirconium acetate as metal precursor and polyvinylpyrrolidone as capping mediator. The present thermal treatment method exclusive of drying process was able to remove the organic compounds efficiently during the calcination process and leave behind the residue of crystalline $\mathrm{ZrO}_{2}$ nanoparticles. 


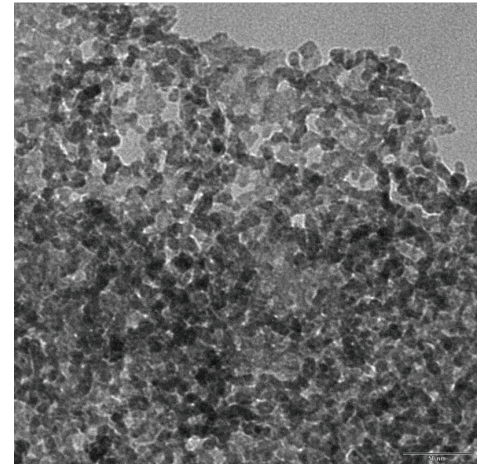

(a)

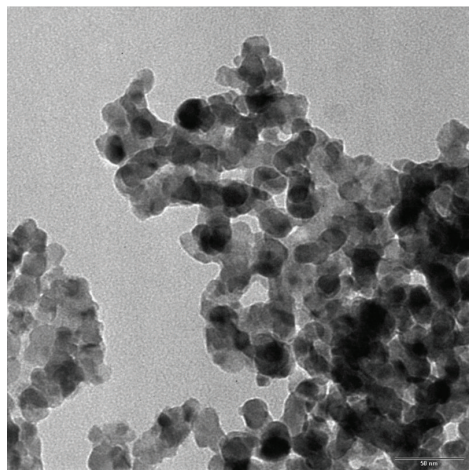

(c)

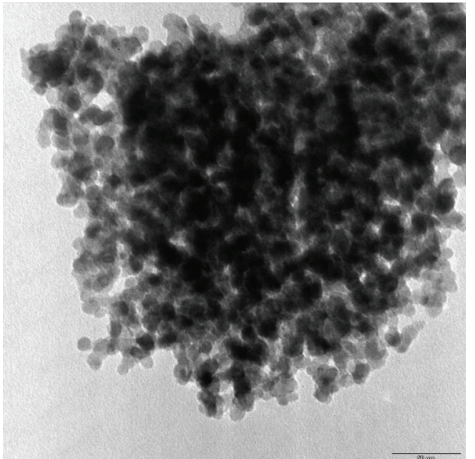

(b)

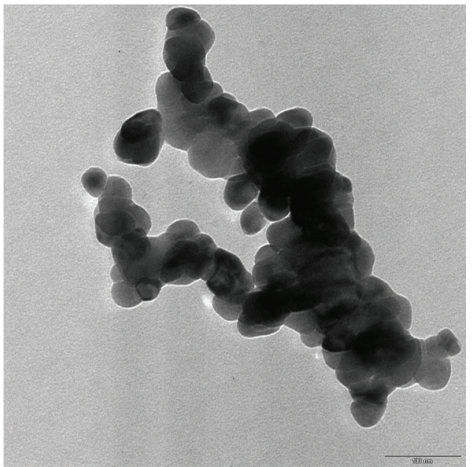

(d)
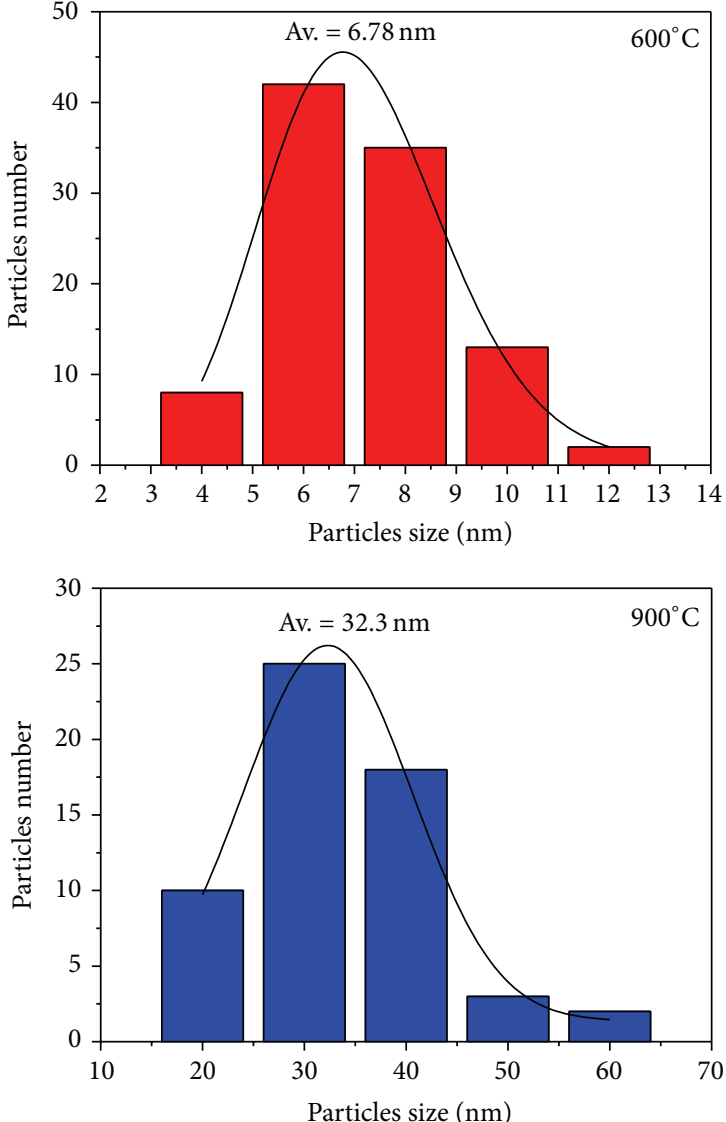

FIGURE 5: TEM images and related size distribution histogram of $\mathrm{ZrO}_{2}$ nanoparticles with different calcination temperatures: (a) 600, (b) 700, (c) 800 , and (d) $900^{\circ} \mathrm{C}$.

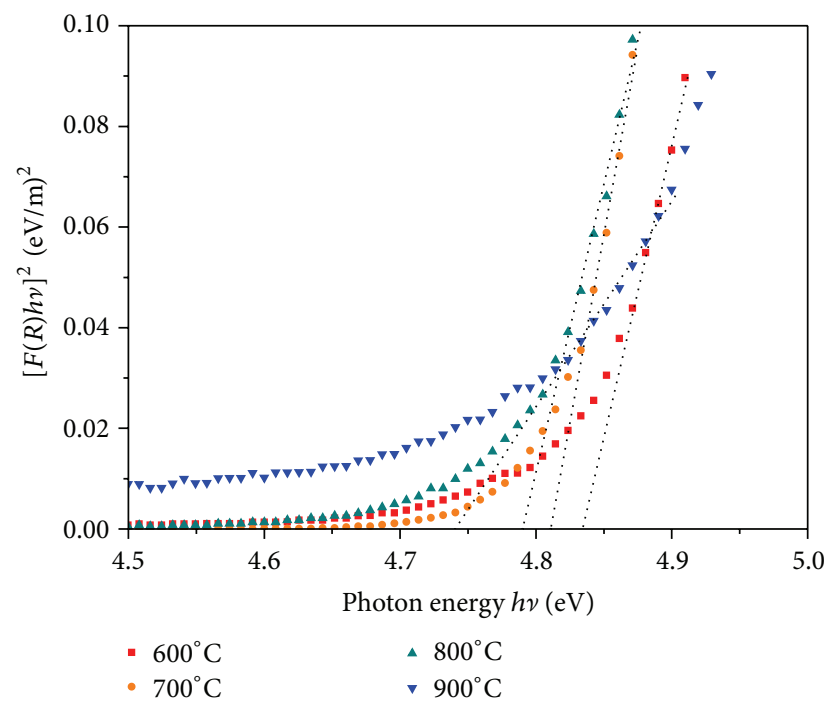

FIgURE 6: Plot of the square of Kubelka-Munk function versus photon energy for calcined samples at different temperatures.

It was also revealed that the calcination temperature is a key factor in controlling the particle size from 7 to $32 \mathrm{~nm}$ when calcination temperature increased from 600 to $900^{\circ} \mathrm{C}$, respectively. The band gap energy of $\mathrm{ZrO}_{2}$ nanoparticles decreased from $4.83 \mathrm{eV}$ at $600^{\circ} \mathrm{C}$ to $4.74 \mathrm{eV}$ at $900^{\circ} \mathrm{C}$ as a result of increasing particle size. This modified thermal treatment to synthesize $\mathrm{ZrO}_{2}$ nanoparticles is a very straightforward, costeffective, and environmentally friendly method, which could be exploited for large-scale industrial fabrication.

\section{Competing Interests}

The authors declare that there are no competing interests regarding the publication of this paper.

\section{Acknowledgments}

The authors would like to acknowledge the technical support from the staff of the Faculty of Science and the Institute of Bioscience (IBS), Universiti Putra Malaysia. This work was financially supported by the Research Management Center (RMC), Universiti Putra Malaysia.

\section{References}

[1] A. Hirvonen, R. Nowak, Y. Yamamoto, T. Sekino, and K. Niihara, "Fabrication, structure, mechanical and thermal properties of zirconia-based ceramic nanocomposites," Journal of the European Ceramic Society, vol. 26, no. 8, pp. 1497-1505, 2006. 
[2] J. C. Ray, D.-W. Park, and W.-S. Ahn, "Chemical synthesis of stabilized nanocrystalline zirconia powders," Journal of Industrial and Engineering Chemistry, vol. 12, no. 1, pp. 142-148, 2006.

[3] J. L. Gole, S. M. Prokes, J. D. Stout, O. J. Glembocki, and R. Yang, "Unique properties of selectively formed zirconia nanostructures," Advanced Materials, vol. 18, no. 5, pp. 664-667, 2006.

[4] G. Dutta, K. P. Hembram, G. M. Rao, and U. V. Waghmare, "Effects of $O$ vacancies and $\mathrm{C}$ doping on dielectric properties of $\mathrm{ZrO} 2 \mathrm{Zr} \mathrm{O}_{2}$ : a first-principles study," Applied Physics Letters, vol. 89, no. 20, Article ID 202904, 2006.

[5] J. C. Garcia, L. M. R. Scolfaro, A. T. Lino et al., "Structural, electronic, and optical properties of $\mathrm{ZrO} 2 \mathrm{Zr} \mathrm{O}_{2}$ from ab initio calculations," Journal of Applied Physics, vol. 100, no. 10, Article ID 104103, 2006.

[6] S. Park, J. M. Vohs, and R. J. Gorte, "Direct oxidation of hydrocarbons in a solid-oxide fuel cell," Nature, vol. 404, no. 6775, pp. 265-267, 2000.

[7] E. C. Subbarao and H. S. Maiti, "Science and technology of zirconia," Advances in Ceramics, vol. 24, pp. 731-737, 1988.

[8] D. He, Y. Ding, H. Luo, and C. Li, "Effects of zirconia phase on the synthesis of higher alcohols over zirconia and modified zirconia," Journal of Molecular Catalysis A: Chemical, vol. 208, no. 1-2, pp. 267-271, 2004.

[9] S. Roy, "Nanocrystalline undoped tetragonal and cubic zirconia synthesized using poly-acrylamide as gel and matrix," Journal of Sol-Gel Science and Technology, vol. 44, no. 3, pp. 227-233, 2007.

[10] T. Chraska, A. H. King, and C. C. Berndt, "On the sizedependent phase transformation in nanoparticulate zirconia," Materials Science and Engineering A, vol. 286, no. 1, pp. 169-178, 2000.

[11] A. U. Limaye and J. J. Helble, "Effect of precursor and solvent on morphology of zirconia nanoparticles produced by combustion aerosol synthesis," Journal of the American Ceramic Society, vol. 86, no. 2, pp. 273-278, 2003.

[12] F. Heshmatpour and R. B. Aghakhanpour, "Synthesis and characterization of nanocrystalline zirconia powder by simple sol-gel method with glucose and fructose as organic additives," Powder Technology, vol. 205, no. 1-3, pp. 193-200, 2011.

[13] H. Keskinen, P. Moravec, J. Smolík, V. V. Levdansky, J. M. Mäkelä, and J. Keskinen, "Preparation of $\mathrm{ZrO}_{2}$ fine particles by CVD process: thermal decomposition of zirconium tertbutoxide vapor," Journal of Materials Science, vol. 39, no. 15, pp. 4923-4929, 2004.

[14] W. Nimmo, D. Hind, N. J. Ali, E. Hampartsoumian, and S. J. Milne, "The production of ultrafine zirconium oxide powders by spray pyrolysis," Journal of Materials Science, vol. 37, no. 16, pp. 3381-3387, 2002.

[15] C. Y. Tai, B.-Y. Hsiao, and H.-Y. Chiu, "Preparation of spherical hydrous-zirconia nanoparticles by low temperature hydrolysis in a reverse microemulsion," Colloids and Surfaces A: Physicochemical and Engineering Aspects, vol. 237, no. 1-3, pp. 105-111, 2004.

[16] R. A. Espinoza-González, D. E. Diaz-Droguett, J. I. Avila, C. A. Gonzalez-Fuentes, and V. M. Fuenzalida, "Hydrothermal growth of zirconia nanobars on zirconium oxide," Materials Letters, vol. 65, no. 14, pp. 2121-2123, 2011.

[17] A. Dittmar, D. L. Hoang, and A. Martin, “TPR and XPS characterization of chromia-lanthana-zirconia catalyst prepared by impregnation and microwave plasma enhanced chemical vapour deposition methods," Thermochimica Acta, vol. 470, no. 1-2, pp. 40-46, 2008.
[18] A. G. Salahudeen, E. Saion, A. H. Shaari, M. A. Kamarudin, N. M. Al-Hada, and A. Kharazmi, "Structural, optical, and magnetic characterization of spinel zinc chromite nanocrystallines synthesised by thermal treatment method," Journal of Nanomaterials, vol. 2014, Article ID 416765, 7 pages, 2014.

[19] M. G. Naseri, E. B. Saion, H. A. Ahangar, and A. H. Shaari, "Fabrication, characterization, and magnetic properties of copper ferrite nanoparticles prepared by a simple, thermal-treatment method," Materials Research Bulletin, vol. 48, no. 4, pp. 14391446, 2013.

[20] M. G. Naseri, E. Saion, and N. K. Zadeh, "The amazing effects and role of PVP on the crystallinity, phase composition and morphology of nickel ferrite nanoparticles prepared by thermal treatment method," International Nano Letters, vol. 3, no. 1, article 19, 8 pages, 2013.

[21] M. G. Naseri, E. B. Saion, H. A. Ahangar, M. Hashim, and A. H. Shaari, "Simple preparation and characterization of nickel ferrite nanocrystals by a thermal treatment method," Powder Technology, vol. 212, no. 1, pp. 80-88, 2011.

[22] P. J. Lee, E. Saion, N. M. Al-Hada, and N. Soltani, "A simple up-scalable thermal treatment method for synthesis of $\mathrm{ZnO}$ nanoparticles," Metals, vol. 5, no. 4, pp. 2383-2392, 2015.

[23] N. M. Al-Hada, E. B. Saion, A. H. Shaari, M. A. Kamarudeen, M. H. Flaifel, and S. A. Gene, "Synthesis, structural and morphological properties of cadmium oxide nanoparticles prepared by thermal treatment method," Advanced Materials Research, vol. 1107, pp. 291-294, 2015.

[24] M. Erfani Haghiri, E. Saion, N. Soltani, and W. S. wan Abdullah, "Thermoluminescence properties of nanostructured calcium borate as a sensitive radiation dosimeter for high radiation doses," Advanced Materials Research, vol. 832, pp. 189-194, 2014.

[25] N. Soltani, A. Dehzangi, A. Kharazmi et al., "Structural, optical and electrical properties of $\mathrm{ZnS}$ nanoparticles affecting by organic coating," Chalcogenide Letters, vol. 11, no. 2, pp. 79-90, 2014.

[26] M. Ranjbar, M. Yousefi, M. Lahooti, and A. Malekzadeh, "Preparation and characterization of tetragonal zirconium oxide nanocrystals from isophthalic acid-zirconium(IV) nanocomposite as a new precursor," International Journal of Nanoscience and Nanotechnology, vol. 8, no. 4, pp. 191-196, 2012.

[27] B. Wiley, Y. Sun, B. Mayers, and Y. Xia, "Shape-controlled synthesis of metal nanostructures: the case of silver," Chemistry-A European Journal, vol. 11, no. 2, pp. 454-463, 2005.

[28] Y. Zheng, Y. Cheng, Y. Wang et al., "Quasicubic $\alpha-\mathrm{Fe}_{2} \mathrm{O}_{3}$ nanoparticles with excellent catalytic performance," The Journal of Physical Chemistry B, vol. 110, no. 7, pp. 3093-3097, 2006.

[29] N. Soltani, E. Saion, M. Z. Hussein, M. Erfani, K. Rezaee, and G. Bahmanrokh, "Phase controlled monodispersed CdS nanocrystals synthesized in polymer solution using microwave irradiation," Journal of Inorganic and Organometallic Polymers and Materials, vol. 22, no. 4, pp. 830-836, 2012.

[30] S. Sakka and R. Almeida, Handbook of Sol-Gel Science and Technology: Processing, Characterization and Applications: Characterization and Properties of Sol-Gel Materials and Products, 2005.

[31] A. K. Singh and U. T. Nakate, "Microwave synthesis, characterization, and photoluminescence properties of nanocrystalline zirconia," The Scientific World Journal, vol. 2014, Article ID 349457, 7 pages, 2014.

[32] J. Ebothe, I. V. Kityk, S. Benet, B. Claudet, K. J. Plucinski, and K. Ozga, "Photoinduced effects in $\mathrm{ZnO}$ films deposited on $\mathrm{MgO}$ substrates," Optics Communications, vol. 267, no. 3, pp. 269-272, 2006 . 

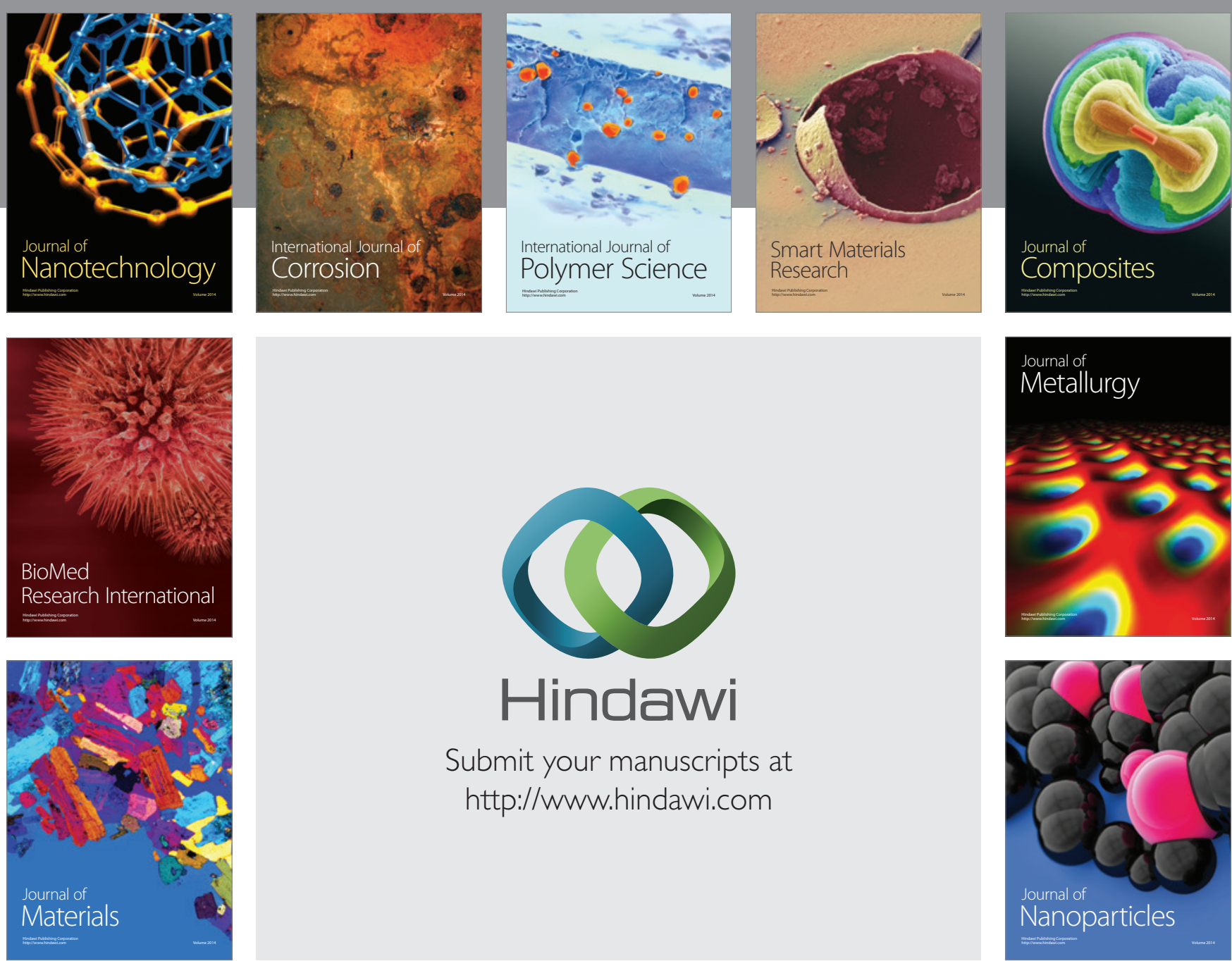

\section{Hindawi}

Submit your manuscripts at

http://www.hindawi.com

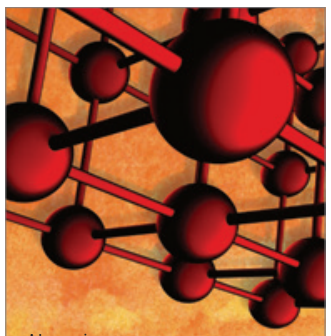

Materials Science and Engineering
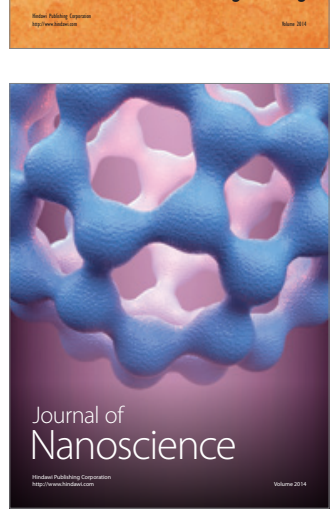
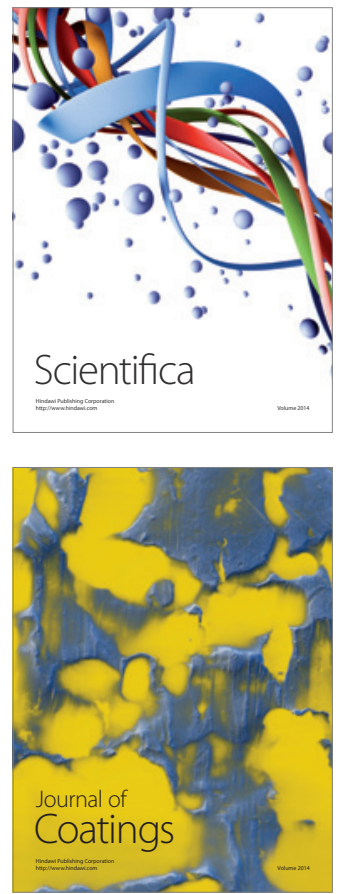
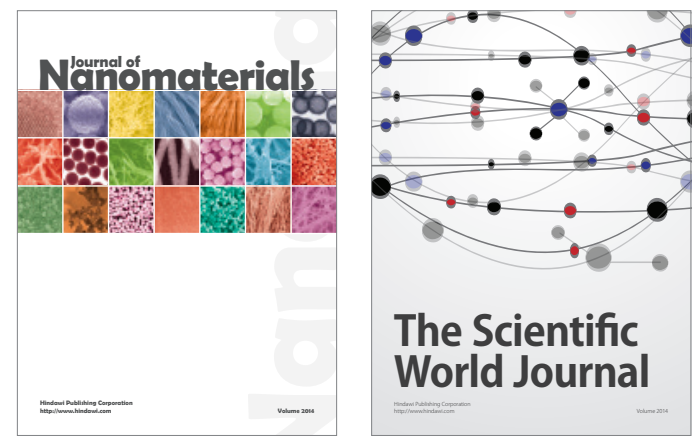

The Scientific World Journal
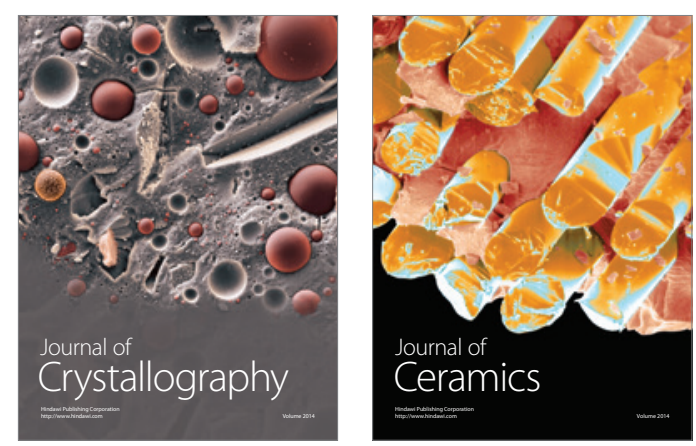
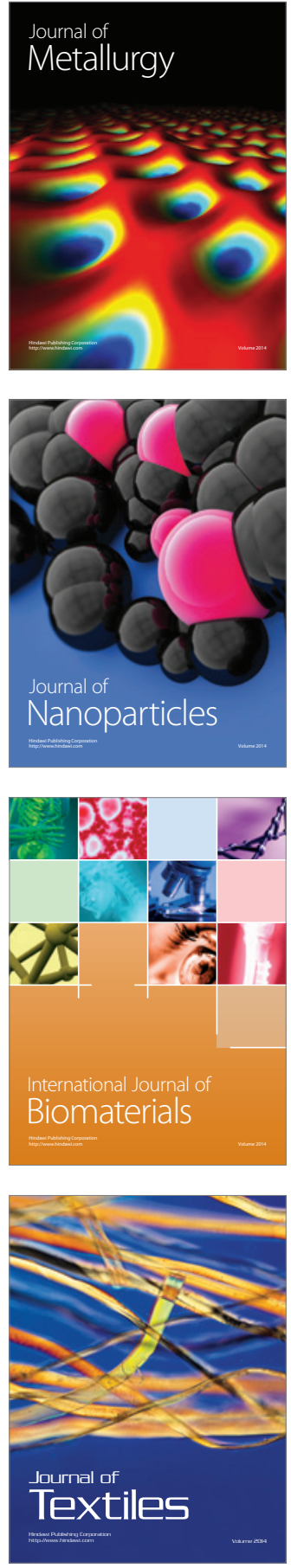